\title{
ANAÏS O CASI NOVELA (un tentempié)
}

Fecha de recepción: 19 de Agosto de 2018

Fecha de aprobación: 24 de diciembre de 2018

\begin{abstract}
00
Estamos en el Lost Forever, un antro de Río de Janeiro donde ponen música ochentera. Me recuerda otro, que aparece en una película entre decadentista y futurista que vi hace algunos años. No me interesó preguntarle su nombre al hombre que me acompaña cuando nos cruzamos en la barra. Ahora, estamos en la penumbra. Suena (o eso parece) Lie to me.
\end{abstract}

\section{1}

El texto literario, por ejemplo, una novela, debe tener un grado de previsibilidad que ofrezca tanto a los que escriben como a los que leen, cierta seguridad, mejor si tiene un argumento lineal con comienzo, desarrollo y final. La incertidumbre, la fragmentariedad, los enredos complejos o truncados no suelen agradar.

No estoy de acuerdo. Pero eso fue lo que me dijo el productor cuando me encargó un par de guiones para una teleserie que abordaría las fantasías sexuales femeninas más comunes, tema que, salvo mi experiencia, que no estoy segura de que sea común ni del todo fantasía o femenina o incluso sexual.

Citar: Brum, M . A. (enero-junio de 2019). Anaïs o casi novela (un tentempié). La Palabra, (34), 115-122. (10) https://doi.org/10.19053/01218530.n34.2019.9535

\section{Maria Alzira Brum}

Escritora brasilera residente en México, ha vivido en distintos países, principalmente en México. Es autora, entre otros de La Orden Secreta de los Ornitorrincos (México Aldus, 2014), Novela suvenir (Mexico, 2013 Editorial, 2014), No hacerlo (México, Librosampleados, 2014) y (Gx2) Realidad Total (en imprenta en México, 2019). Es doctora en Comunicación y Semiótica por la Pontifícia Universidad Católica de São Paulo, y tiene formación en Historia y Filosofía de la ciencia. Se considera en residencia creativa autogestionada permanente y se interesa por los procesos de autoría, creación e interfaces, en que la literatura actúa como transversal a distintos lenguajes, prácticas, saberes, movimientos. 
La bibliografía literaria que consulté en general aborda el sexo, la sexualidad y lo sexual de forma bruta, machista, estereotipada o edulcorada, resultando, en la mayoría de los casos, aburrida. Principalmente porque elude lo que no se adecua a la sintaxis, el azar, las casualidades y diversidades. Como si fuera producida sin inteligencia, es decir, sin la capacidad de cambiar de hábitos o de cambiar los enredos.

De todas formas, tengo otro trabajo, como historiadora, donde estoy en una nómina. Me pagan para registrar testimonios para un proyecto académico sobre el período llamado de transición entre la dictadura y la democracia en Brasil, de finales de los 70 al comienzo de los 90.

Aprendí bastante allí. Nací en 1979 y, antes de juntarme al proyecto, no tenía idea de cuántos 1979 existen dentro de 1979. Asimismo, por ser mal pagado, terminó llevándome a ingresar en la rama de los guiones para teleseries y, como gesto rebelde, a una escritura, digamos, propia.

Me ha ido bien con los testimonios. No puedo decir lo mismo de la teleserie. El productor quería textos creativos, pero a la vez sencillos y convencionales, sin metáforas ni adjetivos ni metonimias ni frases largas ni diálogos difíciles ni repeticiones ni énfasis ni excesos ni cosas por el estilo, así decía, cosas por el estilo. Quería textos diferenciados, así decía, pero que fueran atractivos para el gran público y los anunciantes.

Traté de explicarle que un texto exquisito, oscuro, diferente, que explore otras dimensiones del deseo y las prácticas sexuales, puede ser atractivo. Él me respondió que para estos jueguitos de palabras, así dijo, jueguitos de palabras, ya están las novelas experimentales que apenas se leen, la escritura creativa, el cine arte, los posmodernos, los poetas y una infinidad de mamones, así dijo, mamones, y que, si no podía adecuarme a las exigencias del trabajo, mejor me iba a otra parte.

\section{0}

¿Podría volver a hacerlo?, ¿sexo?, ¿fantasía? ¿teleserie? con el hombre del Lost Forever. Sin embargo, no pienso volver a verlo. Me deshago de mi atuendo, me lavo la cara y me preparo para irme.

Mientras él también trata de recomponerse, me pregunta ¿Cómo te llamas? Anaïs, digo con desgana. Entonces él, que parece un poco cansado, sonríe como si hubiera escuchado algo divertido, tal vez pensando en lo divertido que resulta una dominatrix que se hace llamar Anaïs. Hacerse llamar no, le corrijo mentalmente, porque no le mentí sobre mi nombre. Me llamo Anaïs, así lo registra mi partida de nacimiento. Anaïs, un nombre tan raro y exótico, por lo menos en este país y en esta ciudad, de modo que en esa situación de ¿sexo?, ¿fantasía?, ¿performance? no me doy al trabajo de inventarme otro.

¿En serio?, dice, ¿Por la escritora? Quién sabe, le respondo con una pregunta que es una mentira, porque sé que en el origen de mi nombre no está Anaïs Nin y sí una marca de perfume, Anaïs Anaïs, que se lanzó el año en que nací.

Él sigue sonriendo y mirándome como a una niña pícara y mentirosa que, a su vez, le pregunta, sin disfrazar su aburrimiento. Y tú, ¿cómo te llamas? Su respuesta intenta ser un desafío a cambiar los roles que asumimos hasta ahora. Invéntame un nombre, el que quieras. Veamos, ¿a qué te dedicas? Soy periodista 
y escritor, dice. Esa vez soy yo quien sonríe como diciendo "previsible”, aunque le sigo el juego. ¿Qué tal H?, digo sospechando de que para mí (no para el productor) ya se estropeó el guion, entre otras cosas porque sus presuntos oficios, unidos por una " $y$ " de continuidades y explicaciones, me hacen recordar justo una frase de Nin, de las pocas que me sé de memoria, que dice que la carne contra la carne produce un perfume, pero el roce de las palabras no engendra sino sufrimiento y división, y me entra la necesidad de escapar.

H se había puesto serio, sonreí de nuevo. Me doy cuenta de las arrugas alrededor de sus ojos y boca. Es bastante mayor que yo, aunque la edad no lo resta atractivo. Solo es uno más, pienso, pero digo tan solo un "mucho gusto" y sigue un silencio justo hasta que nos despedimos con un "nos vemos". Sí, claro, en el Lost Forever, donde, imagino, aunque le haya gustado la sesión, que no regresará.

Camino rápido hacia la salida. Al llegar a la puerta, me pongo mis anteojos oscuros. Sigo hasta la Avenida Atlântica, tomo el malecón, donde ya hay gente ejercitándose o camino al trabajo. A cierta altura, paro y me quedo mirando el mar desde donde hace poco ha salido el sol. Siento un resto del olor del hombre letra, del hombre sin nombre, olor a ¿sexo?, ¿fantasía?, ¿perfomance?, mezclándose con los olores de la playa. Aunque trasnochada, me siento casi bien en mi piel, en este verano, en esta playa. Lie to me va dejando poco a poco de sonar junto con las pocas palabras que intercambiamos.

\section{1}

"Para fotografiar un castillo de arena es necesario situarse al mismo nivel del castillo." (La fotografía al alcance de todos).

La foto los muestra en una playa de la zona Sur de Río de Janeiro. No están en la pose clásica, en que se verían de frente, tal vez abrazados, sino de medio perfil, ella a la izquierda, mirándose a los ojos. En el segundo plano se ve un castillo de arena medio deshecho y una bolsa grande a los pies de ella. Al fondo, el mar y el cielo. Sus bocas no sonríen, aunque sus ojos parezcan hacerlo. Por sus expresiones, están a gusto, y las figuras bien delineadas e iluminadas indican que la foto se tomó con la luz favorable de un final de tarde.

Sus ropas y los tonos de la imagen llevan a creer que era un día de media estación en Río de Janeiro, donde ésta a veces dura tan solo algunas horas. Son momentos en que el frío intenta tomar el lugar del calor, que, como si formara parte de la ciudad, se resiste a dejarla. Un día del que se podría decir, usando una frase sacada de un texto célebre, que contiene "todos los hervores del verano y todas las melancolías del invierno".

A mi mamá le encantaban las medias estaciones, aunque esto puede ser un falso recuerdo, porque durante mucho tiempo yo acostumbraba hacer a todos los que la conocieron preguntas sobre su vida. Ahora pienso en lo cursi que resultan juntos "hervores" y "melancolías" cuando son desplazados de la literatura mientras escucho en mi mente la voz de mi mamá diciendo "me encanta".

En la foto, ella viste pantalones claros de mezclilla y blusa negra; el chico, pantalones y campera oscuros, y camiseta negra. En la mano derecha, lleva un cuadernillo. 
Ambos visten de forma discreta, más acorde con lo que se acostumbra en São Paulo, que en ese paisaje en general repleto de prendas ligeras y coloridas. Ambos tienen el cabello castaño, claro el de ella, oscuro y ensortijado o algo desmelenado el de él, quien exhibe cierto frescor adolescente. Se nota que ella le lleva varios años, aunque de todas formas y ángulos se les ve bien, a gusto y, ¿̨por qué no?, como una pareja.

Esta fotografía se tomó el 13 de febrero de 1979 con una cámara Kodak 177 instamatic lente f/11 42 mm, velocidad 1/40 a 1/80, film 126, made in Argentina. Conozco los datos porque aún tengo la cámara. La fecha está apuntada en azul en el dorso de la imagen, que también conservo con cuidado. Incluso la digitalicé, aunque me resisto a mandar hacer copias en papel.

Tal vez tema que, al reproducirla, se pierda algo de lo que la hace tan especial o que los rostros de sus protagonistas terminen en una feria de antigüedades, extraviados de sus referentes, atrapados en el ruido del universo plano del papel, como fondo o decorado.

Esta foto está entre las pocas cosas que quedaron de mi mamá. Juntas, un peluche, algunos discos, fotos que ordené en álbumes y marcos, una cadena, no ocupan más que un rincón de mi pequeño departamento. Si no fuera por la fecha en el dorso, se podría decir que se tomó hace poco, que se trata de una imagen sometida a algún efecto digital vintage.

Sus protagonistas parecen extrañamente atemporales, tal vez anacrónicos o futuristas, para 1979 y podrían materializarse ahora mismo en algún punto de la ciudad y hasta adentrarse en una tienda o un café, sin que se notara que proceden de una fotografía.

Las fotos son potencialidades, fotogramas de películas con muchas secuencias posibles. Se dice que congelan algo. Si es así, en este caso congeló en algún punto de su juventud, el rostro de aquel que se supone es mi papá, a quien nunca conocí en persona. En la imagen, es un chico de poco más de 20 años, varios menos que de los que yo tengo ahora.

Mi mamá aparece como la recuerdo, ni joven ni mayor, algo indefinida, como estos días en los que se mezclan las estaciones y según recuerdo yo u otra persona o un texto célebre o un texto cursi le "encantaban".

Ella tampoco envejeció. Murió a comienzos de 1985, cuando yo recién había cumplido los 5. Sus restos fueron dar en la playa pocos días después de que desapareciera. El informe oficial señaló un posible ahogamiento, dejando en abierto varias hipótesis sobre la causa de su muerte.

"En abierto": espacio suspenso entre el texto y la realidad.

Así, si mi vida fuera un texto o una película, independiente del género, policiaco, ciencia-ficción, posmoderno, biografía, comercial, fantasía, informe oficial, la primera línea sería una frase escrita con luz en un cuadrángulo de papel de 15 por $21 \mathrm{~cm}$. Pura superficie: lisa, escurridiza, impenetrable. 
Mamá hervores y melancolía. Mamá cursi, mamá me encanta. Mamá con su blusa negra en pleno trópico. Mamá ausente, mamá soltera, mamá quién sabe. Mamá jugando a todo. Mamá caminando durante horas por una ciudad donde los mapas a veces se confunden. Mamá en un antro. ¡Game over! Mamá toponimia. Copacabana, Rio Comprido, Rocinha, Tijuca. Méier, Maracanã, Asunción. Mamá geografía. Montañas, lagos, bahías, picos, huecos, vacíos. Mamá isla. El mar cercando mamá. Mamá el agua fría de donde salgo yo. Mamá Billie Jean. Mamá en un viaje alucinógeno, sintiendo la ciudad invertirse y caminando en nubes de algodón de azúcar en un parque de atracciones. Mamá perdiendo su peso. Mamá inmaterial. Mamá playa de fotografía. Mamá nota en el periódico. Mamá estadística. Mamá entropía. Mamá castillo de arena. Mamá deshaciéndose en el mar de Río de Janeiro.

\section{1}

Jamás pude aclarar nada y desistí de buscar. Me quedé con lo que me contaron mis tíos y, principalmente, con el personaje que fui montando a lo largo de los años. Una mamá soltera y trabajadora como muchas otras, que salía de paseo, disfrutaba del ambiente de relajamiento de costumbres que en la época se llamó desbunde, que veía telenovelas (yo prefería las caricaturas del He Man), a quien le gustaba la música (había tantos vinilos en nuestra casa, que no sabría decir cuáles eran suyos y cuáles eran prestados, porque entonces la gente acostumbraba prestarse discos).

\section{0}

Mamá cercada de mercancías paraguayas, abducida por hippies viejos que hacen predicciones apocalípticas en telenovelas. Mamá en una secta futurista con militantes intergalácticos habitando castillos de arena o de Greyskull. Mamá máquina automática programada para parar de funcionar en 1985. Mamá tratando de mandar mensajes al futuro. Mamá sin conexión. Mamá analógica. Mamá Kodak instamatic 1979. Mamá abriendo sus piernas y exponiendo sus pequeños y grandes labios. Mamá vagina rosada de donde escurre agua viscosa y salada. Mamá yéndose, mamá viniéndose. Mamá pariéndome y nombrándome. Nombre raro, nombre ajeno, salto al significante, perfume, roce de la piel. Mamá comienzo y fin de la historia. Mamá inundando la ciudad de goce y nombre. Mamá bautizándome en la bahía de Guanabara. Mamá sacoleira de las estrellas viajando en la pura superficie, en la muerte lisa del papel. Mamá rastro de luz. Mamá ruido de fondo, radiación cósmica. Mamá en la ciudad futura. Mamá Acari, Brás de Pina, Grajaú, Inhaúma, Madureira. Mamá Todos os Santos, Maria da Graça, Caju. Mamá tiendas, carpas, puestos, locales. Mamá y su herencia: mi nombre cosmético.

\section{1}

Fue solo en la adolescencia que tomé conocimiento de mi homónima escritora. Sin embargo, en la escuela ya me había dado cuenta de que Anaïs era un nombre idiosincrático en mi contexto, aunque no el más raro de la lista de asistencia. Aún suena en mi memoria: Sonielson presente, Wellizandra presente, Kalvin y Maikel (eran gemelos) presentes. Iridiayra tampoco es un nombre común y, pensando ahora, 
Paraguaya, aunque sea un sobrenombre, también suena raro (Raro, Iridiayra, sobrenombre, Paraguaya).

Los padres eligen los nombres de sus hijos por razones, y sobre todo no razones, muy diversas. Algunos hacen referencia a personajes históricos, de novelas o telenovelas, (estos últimos han sido particularmente comunes en la época en que nací). Otros solo tienen significado en una historia secreta. Mi nombre se debe a Anaïs Anaïs, perfume descrito en el catálogo del fabricante como "hecho para mujeres sensuales, femeninas y sensibles con una fragancia bouquet floral, combinando notas de flor de naranjo, mandarina, jazmín, sándalo, cedro y ámbar". Supongo que, posiblemente en una versión chafa, se hizo popular entre las clientas de mi mamá, y que ella también lo usaba. Y asimismo que le encantaba como sonaba Anaïs Anaïs (Anaïs, le encantaba, sonaba, sándalo, cedro, jazmín, Anaïs). El mío es, por lo tanto, un nombre que viene de un perfume, puro significante. Es como Sonielson. ¿No es lindo? ¿No es pura poesía? (Sonido, es lindo, Sonielson).

En todo momento, alguien nace de un cuento, una novela, una telenovela, un cómic, una frase cualquiera, un anuncio, una marca. Por eso hay que apropiarnos una y otra vez de nuestros nombres, reinventarlos, darles un nuevo conjunto de referentes, jugar con las imágenes y los signos y manejar de alguna forma lo que hay, o debería haber, de poesía en la historia.

Mi origen es una fotografía, y mi nombre suena a significante, singular, referencia a una calidad, a un perfume, a otra Anaïs.

En cuanto al hombre que aparece en la foto con mi mamá, debe su existencia a mí. Si no fuera mi padre, sería nadie (fuera, sería, padre, nadie), un rostro entre otros en una feria de antigüedades o en la mazmorra del Lost Forever. De modo que soy yo, Anaïs, quien lo rescata de la muerte, del universo finito e ilimitado, de la superficie lisa del papel (Anaïs, superficie, sería). Yo, Anaïs, soy su mamá y le doy existencia, biografía, voz, historia.

\section{0}

Mi relación con las teleseries duró poco. Aunque en principio creí que podría hacerlo razonablemente, luego de varias discusiones en que traté de convencer al productor de mis ideas, él me echó a la calle. Por suerte, mantengo mi trabajo en la universidad.

De todas formas, el despido me dio más tiempo para husmear en internet, entrar en crisis que los doctores atribuyen a mi orfandad, a la falta de una familia cercana, a la falta de novios o novias, a la falta genérica y generalizada, a los vacíos de la vida contemporánea, a mi desadaptación, a los problemas que afligen a los jóvenes y no tan jóvenes contemporáneos y a una larga lista de etcéteras, entre los cuales ser reina en el Lost Forever y escribir en voz propia, algo que no se me había ocurrido antes, tal vez porque ya haya existido una Anaïs escritora y de alguna manera no quiero identificarme ni compararme a ella ni considerarla como mi antes. Si hubiera un antes sería un perfume, un perfume importado, francés o paraguayo, que mi mamá vendía e imagino que usaba, esparciendo un aroma entre dulce y floral en Río de Janeiro. Sería un significante, no una novela ni una biografía. 
Si hubiera un antes, tal vez sería una autora escribiendo desde una ciudad medio inundada. Una autora que escribiese como quien lucha para no ahogarse en un sueño, o en la realidad o en la misma literatura.

\section{1}

Era el año 2011 y yo vivía en Buenos Aires cuando recibí y acepté el encargo, por parte de una editorial limeña, de escribir un texto inspirado en Anaïs Nin o en alguna de sus obras. Este texto sería parte de una colección en que escritores contemporáneos recrearían o comentarían obras de autores del canon.

Casi en el mismo momento en que me llegó esa invitación, cayó una fuerte tormenta y, a las 12 del día, la ciudad oscureció totalmente. En las semanas siguientes, en vez de ponerme en el texto sobre Nin, empecé a escribir, un tanto obsesivamente, uno, que en su mayor parte aún sigue inédito, intitulado Ensayo para no morir en la playa.

Me costó entrar entrarle al texto encargado. Hasta entonces, apenas había leído fragmentos de obras de Nin, que ni siquiera me parecieron atractivos. Es más, veía a su personaje como fechado y sometido al deseo masculino. Sin embargo, al meterme un poco más en sus libros, aprendí algo sobre lo que se concibe como escritura autobiográfica y el proceso de construcción de la autoría.

Finalmente, me vino una idea para el proyecto de la editorial limeña: recrear el personaje de Nin en una historiadora carioca contemporánea, dominatrix aficionada, que, por razones económicas, fungía como escritora de guiones de una teleserie sobre fantasías sexuales femeninas. Una parodia a los textos eróticos de Nin, al lugar común de que a las mujeres nos gusta el "porno con historia", a la centralidad de los enredos e incluso de lo humano en la literatura, con algunas referencias a mi propio texto sobre la inundación y a personajes de la vida y obra de Nin, como Henry Miller y Antonin Artaud.

Experimenté distintas versiones, incluso una con menciones a temas de bandas ochenteras. Los resultados, sin embargo, no me agradaron. El proyecto se abortó enseguida y los textos se quedaron dormidos en mi carpeta de apuntes, donde voy poniendo todo lo que escribo sin orden o intención, hasta que vino una nueva tormenta.

Esa vez no solo duró mucho tiempo, sino que se extendió a toda Sudamérica, del Atlántico al Pacífico. Lima, Río de Janeiro, Montevideo, Guayaquil y varias otras ciudades donde se había escrito lo que yo consideraba mi historia de la literatura latinoamericana o sudaca quedaron medio inundadas.

El agua se llevó mis apuntes, recuerdos, objetos, libros, componentes electrónicos. Traté de salvarme construyendo un texto barco, un texto nave, un texto casa provisional con restos sacados de la inundación. Navegar y sobrevivir en el mar de signos, como estrategia para no morir en la playa.

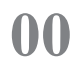

Estos fragmentos, vistos ahora como restos de un naufragio en manos de un arqueólogo, forman una casi nave o casi narrativa. Los recupero como a una embarcación hecha con fragmentos de la "vida y 
obras" de Nin, teleseries, música ochentera, videojuegos, publicidad, literatura bdsm y otros restos de textos abortados por la inundación, incluso uno destinado a una antología de autores nacidos en 1979, que tampoco se editó o cuya invitación habrá sido una broma (aunque de cierta manera muy atinada).

Reciclar tecnologías y ficciones ha sido mi manera de sobrevivir al naufragio, el mío y el de la literatura como canon u oficio u obra del "espíritu humano", al autor y la autoría como identidad y autoridad. Y asimismo mi forma de sublevación, venganza y, por qué no, de exhibirme, ensayarme, mostrarme finalmente en piel y disciplina propia.

\section{1}

Luego de las varias inundaciones, la parte baja de Río de Janeiro es ahora un pantano. Las antiguas áreas nobles están tomadas por palafitos y pandillas que disputan cualquier cosa que se pueda beber, comer, usar, disfrutar. En las zonas altas, sin embargo, sobreviven, fortificados, unos pocos lugares donde se venden mercancías exquisitas.

La ciudad vive bajo un eterno bochorno sin calendario. No hay noche ni día, porque las nubes nunca dejan ver el sol. Las playas desaparecieron, y algunas fueron sustituidas por balnearios artificiales donde brillan soles fake.

Jamás se encontró vida en otros planetas. Sin embargo, aquí mismo, a cada día se descubren o se crean nuevas especies. De hecho, ahora mismo todos somos formas de vida nuevas o en renovación. El planeta es un experimento biotecnológico, que no se sabe si está controlado o se sigue al azar según los caprichos de máquinas interconectadas. La historia y la literatura desaparecieron hace mucho. Las expresiones real y virtual cayeron en desuso.

En medio a la chatarra y a los restos de la historia, la sobrevivencia es un juego. Un juego de muerte o un juego divertido, según se mire. Cualquiera puede hacer lo que le da la gana, mientras pueda pagar por ello. El pago es la esclavitud al servicio de la red.

Los recursos para jugar son casi ilimitados. La medicina ha avanzado hasta la implantación de dispositivos y extensiones bioelectrónicas que mejoran capacidades como la fuerza, la resistencia y la memoria, agudizan sentidos y, principalmente, estimulan y desarrollan puntos de placer y dolor. La comunicación se basa en la transmisión instantánea de signos máquina a máquina, cerebro a máquina, máquina a cerebro. Esa partida se desarrolla en las muchas mazmorras de la ciudad. Entre los jugadores más fuertes en este momento, están las Niñas cerebro. Las probabilidades de vencerlas son de diez para uno. Los perdedores son devorados por ellas.

Las Niñas cerebro mantienen parcialmente la forma humana y están desarrolladas para necesitar carne cruda, aunque también puedan digerir cualquier material sintético añadido a ésta.

Ocuparon, entre otros puntos de la ciudad, el Túnel de Botafogo. Los que buscan emociones fuertes pueden pasar por ahí y, si sobreviven, celebrar en el Lost Forever, un kínder para huérfanos donde aún suena la música ochentera. 